\title{
Sex-specific strategy use and global-local processing: a perspective toward integrating sex differences in cognition
}

\author{
Belinda Pletzer ${ }^{1,2}$ * \\ ${ }^{1}$ Department of Psychology, Paris-Lodron-University Salzburg, Salzburg, Austria \\ ${ }^{2}$ Center for Cognitive Neuroscience, Paris-Lodron University Salzburg, Salzburg, Austria
}

\author{
Edited by: \\ Hubert Vaudry, University of Rouen, \\ France \\ Reviewed by: \\ Rafael Vazquez-Martinez, University \\ of Cordoba, Spain \\ Markus Hausmann, Durham \\ University, UK \\ *Correspondence: \\ Belinda Pletzer, Center of \\ Neurocognitive Research, \\ Paris-Lodron University Salzburg, \\ Hellbrunnerstrasse 34, A - 5020 \\ Salzburg, Austria \\ e-mail: belinda.pletzer@sbg.ac.at
}

This article reviews the literature on sex-specific strategy use in cognitive tasks with the aim to carve out a link between sex differences in different cognitive tasks. I conclude that male strategies are commonly holistic and oriented toward global stimulus aspects, while female strategies are commonly decomposed and oriented toward local stimulus aspects. Thus, the strategies observed in different tasks, may depend on sex differences in attentional focus and hence sex differences in global-local processing. I hypothesize that strategy use may be sex hormone dependent and hence subject to change over the menstrual cycle as evidenced by findings in global-local processing and emotional memory. Furthermore, I propose sex hormonal modulation of hemispheric asymmetries as one possible neural substrate for this theory, thereby building on older theories, emphasizing the importance of sex differences in brain lateralization. The ideas described in the current article represent a perspective toward a unifying approach to the study of sex differences in cognition and their neural correlates.

Keywords: sex differences, cognitive functions, Hemispheric asymmetries, sex hormones, cognitive strategies, global-local processing

\section{HE OR SHE-SHORT INTRODUCTION TO SEX DIFFERENCES IN COGNITION}

For decades it has been debated, whether men and women differ in specific cognitive abilities (e.g., Halpern, 2000; Hyde, 2005; Andreano and Cahill, 2009). The present chapter shall by no means provide an extensive review of these sex differences, but rather introduce those sex differences, which are relevant for the idea presented in this article.

Sex-sensitive tasks have been identified in the domains of spatial, verbal, and memory performance. Thereby the largest sex differences, indicating a male superiority, have been reported for mental rotation tasks (e.g., Voyer and Bryden, 1990; Voyer et al., 1995; Schoning et al., 2007) with effect sizes ranging from 0.25 to 3.04 (Andreano and Cahill, 2009) and spatial navigation tasks (e.g., Galea and Kimura, 1993; Silverman et al., 2000; Saucier et al., 2002) with effect sizes ranging from 0.36 to 1.04 (Andreano and Cahill, 2009). In the domain of verbal abilities, sex differences have been reported for verbal fluency tasks (e.g., Capitani et al., 1998, 1999, 2005) with effect sizes ranging from 0.13 to 0.89 (Mann et al., 1990; Bolla et al., 1998; Loonstra and Sellers, 1998; Halari et al., 2005, 2006; De Frias et al., 2006; Gauthier et al., 2009; Hausmann et al., 2009; Soleman et al., 2013; Hirnstein et al., 2014), verbal memory tasks (e.g., Kimura and Seal, 2003; Yonker et al., 2003) with effect sizes ranging from 0.18 to 0.97 (Andreano and Cahill, 2009). But non-significant effects and effects to the opposite have also been reported (e.g., Kimura and Seal, 2003; Yonker et al., 2003; Munro et al., 2012). Sex differences have also been observed in autobiographic memory (Pillemer et al., 2003) and other aspects of episodic memory, like the recognition of odors (e.g., Oberg et al., 2002), faces (e.g., Bengner et al., 2006), objects, and pictures (e.g., Galea and Kimura, 1993), as well as for a variety of higher order cognitive functions (Harness et al., 2008; Li et al., 2009; Huster et al., 2011).

However, several of these findings have been questioned by theorists arguing that sex differences are overall small and negligible and within-group variation is stronger than the variation between groups (Hyde, 2006; Hyde and Linn, 2006). For example, a meta-analysis by Hyde and Linn (1988) yielded only a very weak effect size $(d=0.11)$ for sex differences in verbal functions across 165 studies using different verbal tasks. However, whether overall performance differences between men and women exist, does not explain why and how cognition differs between the sexes.

First, there is an increasing interest in the actions of sex hormones on the brain (De Frias et al., 2006), which may affect sex differences in cognitive tasks, emotional processing or personality. However, sex hormone levels, especially in women are not constant, but subject to changes due to endogenous hormonal fluctuations (menstrual cycle) or the application of synthetic steroids (hormonal contraception). Hence, for some tasks we do of course expect within-group variation in cognitive performance that may mask differences between groups, if these factors are not adequately controlled for (see also Pletzer et al., 2011, 2014a). It has for example been demonstrated that women perform better on mental rotation and other spatial tasks during the early follicular phase (low estrogen and progesterone) or if on hormonal contraception, while verbal abilities are also increased in hormonal contraceptive users as well as during the luteal cycle phase (high estrogen and progesterone) (Hampson, 1990; 
e.g., Mordecai et al., 2008; Wharton et al., 2008; Dadin et al., 2009). However, as outlined by a recent review (Sundstrom et al., this topic), these findings are not always replicable, also due to inconsistencies in the definition of cycle phases.

Second, it has been argued in the personality domain, that one cannot conclude from the comparison of isolated personality dimensions that differences between men and women in personality are small (Del Giudice et al., 2012). Rather personality has always been viewed as a multidimensional construct and research on sex differences should approach it as such. Personality dimensions do not affect our behavior individually. It is their relative manifestation and the interactions between different traits that form our behavior as a whole and these relations and interactions are what should be studied with respect to individual differences, as e.g., sex differences. I propose that the same holds true for the cognitive domain. While sex differences in some abilities may be small and sex differences are more pronounced in some abilities than others (e.g., spatial abilities), it is our cognitive profile, i.e., the common action and interaction of all aspects of cognition that shape our everyday life performance. Therefore, research on sex differences should advance from studying some cognitive abilities as separate entities, but move toward a more integrative approach and try to link sex differences across singular tasks. By identifying similarities between sex differences in various tasks, we may derive common principles and ideally link these principles to neural substrates.

Third, an absence of sex differences at the behavioral level does not necessarily imply that men and women did process a specific task in the same way. For example, several neuroimaging studies demonstrate sex differences in brain activation during a task, while not observing behavioral sex differences (e.g., Weiss et al., 2003; Schoning et al., 2007). Many authors have argued that men and women use different cognitive strategies (e.g., Cochran and Wheatley, 1989) employing different approaches. A common method is to utilize different instructions or the use of different stimulus materials or categories that favor the use of one strategy over another. For example, Sharps et al. (1993) were able to demonstrate that sex differences in a mental rotation task disappear, if they used non-spatial instructions and a female superiority in object location memory disappears, if the labeling of items is not possible (Postma et al., 2004). The use of different strategies may also be suggested by eye-tracking studies, if men and women focus on different stimulus aspects (e.g., Hampson, 1990). Another source of information regarding sex-specific strategy use are participants self-reports (e.g., Gluck, 2003). The following chapter will summarize several examples, where men and women approach a task with different strategies. As I will outline, it may be the nature of these differential strategies that links sex differences across tasks and to brain organization.

\section{HOLISTIC OR DECOMPOSED-DISSOCIATION OF SEX-SPECIFIC STRATEGIES ACROSS TASKS}

The dissociation of cognitive strategies between men and women has been studied most extensively in spatial tasks. In the mental rotation task for example, it has been deduced from participants self-reports that men tend to use a more holistic "Gestalt" approach, while women use a segmentary strategy of rotating parts of the stimuli separately (Gluck, 2003; Pena et al., 2008;
Rilea, 2008). In spatial navigation, it has been demonstrated using participants self-reports and different instructions, that men focus on distal landmarks and use allocentric coordinates, while women focus on local landmarks and use egocentric coordinates (Galea and Kimura, 1993; Lawton, 1994, 2001; Lawton et al., 1996). Men outperform women in both real world and 2D-matrix navigation, when directions are given in Euclidean terms using allocentric coordinates (Saucier et al., 2002). On the other hand, women outperform men, when directions are given using landmark information and egocentric coordinates (Saucier et al., 2002) and sex differences in virtual navigation decline the more landmark information is available (Andersen et al., 2012). For navigation, the sex-specific strategy dissociation has been corroborated by eye-tracking evidence. In a virtual water maze, men explore more space, while women show longer fixation durations (Mueller et al., 2008). Furthermore, the allocentric strategy has successfully been related to mental rotation performance (Saucier et al., 2002), demonstrating that a more global strategy is beneficial in spatial tasks.

A dissociation between global and local strategies has however also been described for a variety of spatial-related and nonspatial tasks. For example, using different stimulus categories, we recently described a strategy dissociation in a number comparison task (Pletzer et al., 2013), suggesting that men process multidigit numbers in a more holistic fashion (whole numbers), while women process decade and unit digit magnitudes separately.

Likewise, eye-tracking evidence demonstrated that during face and emotion recognition women fixate more strongly on the eyes, independent of view-point, while men tend to focus their gaze more toward the nose in frontal views and the cheeks in profiles, i.e., the view-specific center-of-gravity (e.g., Saether et al., 2009).

The common denominator across the tasks and strategies described so far, is that the sex specific strategies can be linked to visuospatial attention in that participants either self-report their focus of attention, their focus of attention is actively directed toward particular stimulus aspects via different instructions or the use of different stimulus categories, or their focus of attention is recorded using eye-tracking evidence.

Thereby, male strategies appear to share the common feature of being oriented toward more global stimulus features or aspects of the task, i.e., they can be described as holistic. Female strategies however appear to be oriented toward more local stimulus features and can thus be described as decomposed. Consequently, sex-specific strategy use may be linked to sex differences in attentional focus, an idea which will be pursued in the next chapter.

The global-local dissociation has been studied particularly well in the context of emotional memory. It has repeatedly been demonstrated that men show better memory of the gist of an emotional story, while women better remember the details of an emotional story (e.g., Cahill, 2003; Cahill et al., 2004; Nielsen et al., 2011). Thereby, the gist and the detail refer to aspects of visual scenes, which makes it plausible that the strategies described for emotional memory are also linked to differences in visuo-spatial attention.

It is an interesting question, whether sex-specific strategies in other tasks that cannot as easily be related to visuo-spatial attention, can also be linked to this principle. It has for example repeatedly been demonstrated that during verbal fluency tasks, 
men produce larger clusters (series of words that belong to the same semantic or phonological category), while women tend to switch more often between different categories (Weiss et al., 2006). Category size has been used as one indicator of conceptual global-local processing, as described in the next chapter (Darwent et al., 2010).

In summary, sex-specific strategy use has been reported for almost every cognitive task for which sex differences in performance have been reported. For several tasks, these strategies may be generalizable via a principle in visuo-spatial attention with male strategies being oriented toward global stimulus aspects and female strategies being oriented toward local stimulus aspects. Note however, that only few of the studies described above (Nielsen et al., 2011, 2013; Pletzer et al., 2013) controlled for menstrual cycle phase, hormonal contraceptive use or sex hormone levels. In emotional memory for example, the focus on the details of an emotional story in women appears to be particularly enhanced during the luteal cycle phase, when women's estradiol and progesterone levels are high (Nielsen et al., 2011, 2013). Thus, for several of these tasks, a hormonal modulation of sex-specific strategy use remains yet to be established.

\section{GLOBAL OR LOCAL-SEX DIFFERENCES IN ATTENTIONAL FOCUS}

Individual differences in global-local processing are wellestablished (Forster and Dannenberg, 2010a,b). Perceptual global-local processing refers to the tendency to process visual stimuli as a whole or in parts, whereas conceptual global-local processing refers to the tendency to think in more concrete or abstract terms (Darwent et al., 2010).

Perceptual global-local processing is traditionally studied using hierarchical stimuli (Navon paradigm), i.e., a global structure made up of local parts (Navon, 1977). These stimuli allow assessing global and local processing independently of each other and in their interaction, since participants attention can be directed toward either the global or the local level. Thereby, participants are asked to respond if a certain predefined target appears at a specified level. From experiments with this paradigm, the concept of global precedence was developed (Navon, 1977, 1981), which includes among others the observation that reactions to global targets are faster than reactions to local targets (global advantage).

If sex differences in cognitive tasks are based on sex differences in attentional focus, these differences should be apparent in a Navon paradigm. Indeed several findings have been published that support this view. Using a divided attention paradigm, a local advantage has been demonstrated in women that was absent in men (Roalf et al., 2006), while in a selective attention paradigm, a global advantage has been demonstrated in men that was absent in women (Razumnikova and Vol'f, 2011). However, these findings have been questioned by a lack of sex differences in global advantage using hierarchical line/shape stimuli (Kimchi et al., 2009) or a similarity judgment task (Basso and Lowery, 2004).

In a recent study designed to resolve inconsistencies between these previous reports, we demonstrated that the reduced global advantage in women is strongly dependent on hormonal status (Pletzer et al., 2014b). Women in their luteal phase (high estradiol and progesterone) showed reduced global advantage in comparison to men, but also in comparison to women in their follicular phase (low estradiol and progesterone) and hormonal contraceptive users. Furthermore, global advantage was positively related to testosterone levels, but negatively to progesterone levels, while no relationship was observed with estradiol levels. Thus, an enhanced focus on the global aspects of hierarchical stimuli is probably facilitated by testosterone, while an enhanced focus on the local aspects of hierarchical stimuli is probably facilitated by progesterone. This may explain why only women in their luteal cycle phase, i.e., women with elevated progesterone levels, showed a reduction in global advantage compared to men.

Conceptual global-local processing is traditionally studied via construal level tasks (Darwent et al., 2010), e.g., asking participants to group a given set of words into categories, whereby category size is used as an indicator of global-local processing. To the best of our knowledge, sex differences have not been as explicitly studied, nor consistently been reported for this task, although certain similarities to the verbal fluency or verbal memory tasks are apparent. However, a link between perceptual and conceptual global-local processing has been proposed (Forster, 2009; Darwent et al., 2010; Forster and Dannenberg, 2010a,b). Thus, it may be worth investigating a possible link of sex differences in strategy selection between visuo-spatial and verbal tasks. There is for example evidence for sex differences in the relation between creativity and perceptual global-local processing (Razumnikova and Vol'f, 2012).

Furthermore, several psychological (e.g., mood) or social (e.g., stereotype threat) factors have been identified that can affect the size of sex differences in cognitive tasks (e.g., Hausmann et al., 2009; Hirnstein et al., 2014). Global-local processing has been linked to mood (Basso et al., 1996) and gender stereotype activation (Anderson, 2011), which suggests that these factors should also been taken into account when establishing a link between sex-specific strategy use and global-local processing across different tasks.

\section{LEFT OR RIGHT/COUPLING OR DECOUPLING-HEMISPHERIC INTERPLAY AS NEURAL SUBSTRATE OF SEX DIFFERENCES?}

Results from visual hemifield (e.g., Robertson and Lamb, 1991), EEG (e.g., Johannes et al., 1996) and fMRI studies (Fink et al., 1996) indicate, that the right hemisphere shows an advantage for processing of the global level, while the left hemisphere shows an advantage for processing of the local level.

Hemispheric asymmetries have also been assessed for several of the cognitive functions discussed above as being subject to sexspecific strategy use (for reviews see e.g., Wada, 2009; Renteria, 2012). For example, verbal functions appear to be left-lateralized, while visuospatial functions appear to be right-lateralized. Such a lateralization of brain functions is mostly assumed to rely on inter-hemispheric inhibition (Chiarello and Maxfield, 1996), with the hemisphere dominant for a task inhibiting the nondominant hemisphere. Since a right-hemispheric dominance for visuo-spatial attention has been reported (Heilman and Van Den Abell, 1980; Heilman et al., 1983), the lateralization of globallocal processing may explain the general observation of a global advantage. The dominant right hemisphere is responsible for 
global processing and inhibits the non-dominant left hemisphere responsible for local processing.

Furthermore, sex differences in brain lateralization have received much attention. Some authors argue that hemispheric asymmetries are more pronounced in men than in women and that a stronger variation in hemispheric asymmetries is apparent in women as compared to men (for reviews see McGlone, 1980; Hausmann and Bayer, 2010; Renteria, 2012). However, a metaanalysis by Voyer (Voyer et al., 2012) suggests that this idea may not hold across tasks and that sex differences in the lateralization of verbal and visuo-spatial functions are modulated by modality (visual vs. auditory). Hausmann and Bayer (2010) argue that sex differences in hemispheric asymmetries may be modulated by intra- and inter-individual variations in sex hormone levels. A menstrual cycle dependent modulation of lateralization may explain the stronger variation in hemispheric asymmetries within the female group (Hausmann and Bayer, 2010).

In that respect it has been demonstrated that the lateralization of brain functions is particularly reduced during the luteal cycle phase, when a woman's estradiol and progesterone levels are high (Hausmann and Gunturkun, 2000). This reduction in hemispheric lateralization has originally been attributed to a progesterone-mediated reduction in inter-hemispheric inhibition, termed progesterone-mediated inter-hemispheric decoupling (Hausmann and Gunturkun, 2000). Therefore, we hypothesized that the reduction in global advantage we observed during the luteal cycle phase (Pletzer et al., 2014b), was mediated via the progesterone-dependent reduction of inter-hemispheric inhibition during global-local processing. However, recent studies stress the role of estradiol in modulating inter-hemispheric communication (Hausmann and Gunturkun, 2000; Weis et al., 2008; Weis and Hausmann, 2010; Hausmann et al., 2013) over the menstrual cycle and this theory has recently been extended to include sex hormone modulations of inter-hemispheric excitation and integration (Bayer et al., 2008). A relationship between global advantage and estradiol was not observed in our previous study (Pletzer et al., 2014b). A reduction of inter-hemispheric inhibition during high-hormone phases has been demonstrated in visual hemifield (Hausmann and Gunturkun, 2000), and fMRI experiments (Weis et al., 2008). In line with this idea, sex-specific hemispheric specialization has recently been demonstrated during global-local processing in a Navon paradigm (Lee et al., 2012), as well as during emotional memory (Cahill, 2007).

Other theories stress, that some sex hormones may enhance the functioning and intra-hemispheric integration of a particular hemisphere (e.g., Hampson, 1990). It has e.g., been proposed that the "female" sex hormone estrogen enhances left-hemisphere functioning, while the "male" sex hormone testosterone has been discussed to enhance right-hemisphere functioning (e.g., Toga and Thompson, 2003). The latter view is in line with our observation that high levels of testosterone are associated with enhanced global advantage.

While a complete picture of how sex hormones interact with inter-hemispheric communication has yet to emerge, several results indicate that sex hormones modulate inter-hemispheric communication (see Hausmann and Bayer, 2010 for a review). We hypothesize that via this modulation, sex hormones affect global and local attention, which may relate to cognitive strategies in several cognitive tasks. To establish a more complete picture on the sex hormonal modulation of lateralization and the link between lateralization and cognitive strategies, hemispheric asymmetries should be taken into account when studying sex differences in cognitive strategies.

\section{CONCLUSIONS}

In summary, it has been found, that sex specific strategies share several features over different cognitive tasks and can be described as global/holistic in men and local/decomposed in women and linked to sex-differences in global-local processing. I hypothesized that sex differences in the lateralization of brain functions accompany these strategies as a result of sex hormone modulation of transcallosal neurotransmission. Empirical evidence linking strategy to lateralization and demonstrating hormone-dependent modulation of strategies as well as lateralization is still lacking for several of the tasks described. This shifts the emphasis from a descriptive comparison of men and women to the question how sex hormones modulate cognition as a whole and can only be answered by an adequate understanding of the changes occurring over the course of the menstrual cycle. The idea of the corpus callosum, gating attentional focus and thereby guiding strategy use in a variety of cognitive tasks represents a perspective toward a link between sex differences in different cognitive tasks.

\section{REFERENCES}

Andersen, N. E., Dahmani, L., Konishi, K., and Bohbot, V. D. (2012). Eye tracking, strategies, and sex differences in virtual navigation. Neurobiol. Learn. Mem. 97, 81-89. doi: 10.1016/j.nlm.2011.09.007

Anderson, S. P. (2011). The Effects of Global and Local Processing on Gender Stereotype Activation and Inhibition. Minnesota: UMI Disseration Publishing.

Andreano, J. M., and Cahill, L. (2009). Sex influences on the neurobiology of learning and memory. Learn. Mem. 16, 248-266. doi: 10.1101/lm.918309

Basso, M. R., and Lowery, N. (2004). Global-local visual biases correspond with visual-spatial orientation. J. Clin. Exp. Neuropsychol. 26, 24-30. doi: 10.1076/jcen.26.1.24.23939

Basso, M. R., Schefft, B. K., Ris, M. D., and Dember, W. N. (1996). Mood and global-local visual processing. J. Int. Neuropsychol. Soc. 2, 249-255. doi: $10.1017 /$ S1355617700001193

Bayer, U., Kessler, N., Gunturkun, O., and Hausmann, M. (2008). Interhemispheric interaction during the menstrual cycle. Neuropsychologia 46, 2415-2422. doi: 10.1016/j.neuropsychologia.2008.02.028

Bengner, T., Fortmeier, C., Malina, T., Lindenau, M., Voges, B., Goebell, E., et al. (2006). Sex differences in face recognition memory in patients with temporal lobe epilepsy, patients with generalized epilepsy, and healthy controls. Epilepsy Behav. 9, 593-600. doi: 10.1016/j.yebeh.2006.08.021

Bolla, K. I., Gray, S., Resnick, S. M., Galante, R., and Kawas, C. (1998). Category and letter fluency in highly educated older adults. Clin. Neuropsychol. 12, 330-338. doi: 10.1076/clin.12.3.330.1986

Cahill, L. (2003). Sex- and hemisphere-related influences on the neurobiology of emotionally influenced memory. Prog. Neuropsychopharmacol. Biol. Psychiatry 27, 1235-1241. doi: 10.1016/j.pnpbp.2003.09.019

Cahill, L. (2007). "Human brain imaging studies of emotional memory: uncovering influences of sex and hemisphere," in Neural Plasticity and Memory: from Genes to Brain Imaging, ed F. Bermudez-Rattoni (Boca Raton, FL: CRC Press), 311-324. doi: 10.1201/9781420008418.ch15

Cahill, L., Gorski, L., Belcher, A., and Huynh, Q. (2004). The influence of sex versus sex-related traits on long-term memory for gist and detail from an emotional story. Conscious. Cogn. 13, 391-400. doi: 10.1016/j.concog.2003.11.003

Capitani, E., Barbarotto, R., and Laiacona, M. (2005). Gender differences and the brain representation of semantic knowledge. Brain Lang. 95, 56-57. doi: 10.1016/j.bandl.2005.07.022 
Capitani, E., Laiacona, M., and Barbarotto, R. (1999). Gender affects word retrieval of certain categories in semantic fluency tasks. Cortex 35, 273-278. doi: 10.1016/S0010-9452(08)70800-1

Capitani, E., Laiacona, M., and Basso, A. (1998). Phonetically cued wordfluency, gender differences and aging: a reappraisal. Cortex 34, 779-783. doi: 10.1016/S0010-9452(08)70781-0

Chiarello, C., and Maxfield, L. (1996). Varieties of interhemispheric inhibition, or how to keep a good hemisphere down. Brain Cogn. 30, 81-108. doi: 10.1006/brcg.1996.0006

Cochran, K. F., and Wheatley, G. H. (1989). Ability and sex-related differences in cognitive strategies on spatial tasks. J. Gen. Psychol. 116, 43-55. doi: 10.1080/00221309.1989.9711109

Dadin, C. O., Salgado, D. R., and Fernandez, E. A. (2009). Natural sex hormone cycles and gender differences in memory. Actas Esp. Psiquiatr. 37, 68-74.

Darwent, K. M., Fujita, K., and Wakslak, C. J. (2010). On the role of abstraction in global and local processing phenomena. Psychol. Inq. 21, 198-202. doi: 10.1080/1047840X.2010.502094

De Frias, C. M., Nilsson, L. G., and Herlitz, A. (2006). Sex differences in cognition are stable over a 10 -year period in adulthood and old age. Neuropsychol. Dev. Cogn. B Aging Neuropsychol. Cogn. 13, 574-587. doi: $10.1080 / 13825580600678418$

Del Giudice, M., Booth, T., and Irwing, P. (2012). The distance between mars and venus: measuring global sex differences in personality. PLoS ONE 7:e29265. doi: 10.1371/journal.pone.0029265

Fink, G. R., Halligan, P. W., Marshall, J. C., Frith, C. D., Frackowiak, R. S., and Dolan, R. J. (1996). Where in the brain does visual attention select the forest and the trees? Nature 382, 626-628. doi: 10.1038/38 $2626 \mathrm{a} 0$

Forster, J. (2009). Relations between perceptual and conceptual scope: how global versus local processing fits a focus on similarity versus dissimilarity. J. Exp. Psychol. Gen. 138, 88-111. doi: 10.1037/a0014484

Forster, J., and Dannenberg, L. (2010a). GLOMO(sys): a systems account of global versus local processing. Psychol. Inq. 21, 175-197. doi: 10.1080/1047840X.2010.487849

Forster, J., and Dannenberg, L. (2010b). GLOMO(sys): specifications of a global model on processing styles REPLY. Psychol. Inq. 21, 257-269. doi: 10.1080/1047840X.2010.507989

Galea, A. M. L., and Kimura, D. (1993). Sex-differences in route-learning. Pers. Individ. Dif. 14, 53-65. doi: 10.1016/0191-8869(93)90174-2

Gauthier, C. T., Duyme, M., Zanca, M., and Capron, C. (2009). Sex and performance level effects on brain activation during a verbal fluency task: a functional magnetic resonance imaging study. Cortex 45, 164-176. doi: 10.1016/j.cortex.2007.09.006

Gluck, J. F. S. (2003). Spatial strategy selection: interesting incremental information. Int. J. Test. 3, 293-308. doi: 10.1207/S15327574IJT0303_7

Halari, R., Hines, M., Kumari, V., Mehrotra, R., Wheeler, M., Ng, G., et al. (2005). Sex differences and individual differences in cognitive performance and their relationship to endogenous gonadal hormones and gonadotropins implications for schizophrenia. Schizophr. Bull. 31, 511-511. doi: 10.1037/07357044.119.1.104

Halari, R., Sharma, T., Hines, M., Andrew, C., Simmons, A., and Kumari, V. (2006). Comparable fMRI activity with differential behavioural performance on mental rotation and overt verbal fluency tasks in healthy men and women. Exp. Brain Res. 169, 1-14. doi: 10.1007/s00221-005-0118-7

Halpern, D. F. (2000). Sex Differences in Cognitive Abilities, 3rd Edn. Mahwah, NJ: Erlenbaum Associates.

Hampson, E. (1990). Variations in sex-related cognitive-abilities across the menstrual-cycle. Brain Cogn. 14, 26-43. doi: 10.1016/0278-2626(90)90058-V

Harness, A., Jacot, L., Scherf, S., White, A., and Warnick, J. E. (2008). Sex differences in working memory. Psychol. Rep. 103, 214-218. doi: 10.2466/pr0.103.1. 214-218

Hausmann, M., and Bayer, U. (2010). "Sex hormonal effects on hemispheric asymmetry and interhemispheric interaction," In The Two Halves of the Brain: Information Processing in the Cerebral Hemispheres, eds 1. K. Hugdah and R. Westerhausen (Cambridge, MA: MIT Press), 287-312.

Hausmann, M., and Gunturkun, O. (2000). Steroid fluctuations modify functional cerebral asymmetries: the hypothesis of progesterone-mediated interhemispheric decoupling. Neuropsychologia 38, 1362-1374. doi: 10.1016/S0028-3932(00)00045-2
Hausmann, M., Hamm, J. P., Waldie, K. E., and Kirk, I. J. (2013). Sex hormonal modulation of interhemispheric transfer time. Neuropsychologia 51, 1734-1741. doi: 10.1016/j.neuropsychologia.2013.05.017

Hausmann, M., Schoofs, D., Rosenthal, E. S. H., and Jordan, K. (2009). Interactive effects of sex hormones and gender stereotypes on cognitive sex differences-a psychobiosocial approach. Psychoneuroendocrino 34, 389-401. doi: 10.1016/j.psyneuen.2008.09.019

Heilman, K. M., and Van Den Abell, T. (1980). Right hemisphere dominance for attention: the mechanism underlying hemispheric asymmetries of inattention (neglect). Neurology 30, 327-330. doi: 10.1212/WNL.30.3.327

Heilman, K. M., Watson, R. T., Bower, D., and Valenstein, E. (1983). Righthemisphere dominance for attention. Rev. Neurol. (Paris). 139, 15-17.

Hirnstein, M., Andrews, L. C., and Hausmann, M. (2014). Gender-stereotyping and cognitive sex differences in mixed- and same-sex groups. Arch. Sex. Behav. 43, 1663-1673. doi: 10.1007/s10508-014-0311-5

Huster, R. J., Westerhausen, R., and Herrmann, C. S. (2011). Sex differences in cognitive control are associated with midcingulate and callosal morphology. Brain Struct. Funct. 215, 225-235. doi: 10.1007/s00429-010-0289-2

Hyde, J. S. (2005). The gender similarities hypothesis. Am. Psychol. 60, 581-592. doi: 10.1037/0003-066X.60.6.581

Hyde, J. S. (2006). Gender similarities still rule. Am. Psychol. 61, 641-642. doi: 10.1037/0003-066X.61.6.641b

Hyde, J. S., and Linn, M. C. (1988). Gender differences in verbal-ability - a metaanalysis. Psychol. Bull. 104, 53-69. doi: 10.1037/0033-2909.104.1.53

Hyde, J. S., and Linn, M. C. (2006). Diversity - gender similarities in mathematics and science. Science 314, 599-600. doi: 10.1126/science.1132154

Johannes, S., Wieringa, B. M., Matzke, M., and Munte, T. F. (1996). Hierarchical visual stimuli: electrophysiological evidence for separate left hemispheric global and local processing mechanisms in humans. Neurosci. Lett. 210, 111-114. doi: 10.1016/0304-3940(96)12686-0

Kimchi, R., Amishav, R., and Sulitzeanu-Kenan, A. (2009). Gender differences in global-local perception? Evidence from orientation and shape judgments. Acta Psychol. (Amst). 130, 64-71. doi: 10.1016/j.actpsy.2008.10.002

Kimura, D., and Seal, B. N. (2003). Sex differences in recall of real or nonsense words. Psychol. Rep. 93, 263-264. doi: 10.2466/pr0.2003.93.1.263

Lawton, C. A. (1994). Gender differences in way-finding strategies - relationship to spatial ability and spatial anxiety. Sex Roles 30, 765-779. doi: 10.1007/BF01544230

Lawton, C. A. (2001). Gender and regional differences in spatial referents used in direction giving. Sex Roles 44, 321-337. doi: 10.1023/A:1010981616842

Lawton, C. A., Charleston, S. I., and Zieles, A. S. (1996). Individual- and genderrelated differences in indoor wayfinding. Environ. Behav. 28, 204-219. doi: $10.1177 / 0013916596282003$

Lee, J., Chung, D., Chang, S., Kim, S., Kim, S. W., Park, H., et al. (2012). Gender differences revealed in the right posterior temporal areas during Navon letter identification tasks. Brain Imaging Behav. 6, 387-396. doi: 10.1007/s11682-0129153-8

Li, S. R. C., Zhang, S., Duann, J. R., Yan, P. S., Sinha, R., and Mazure, C. M. (2009). Gender differences in cognitive control: an extended investigation of the stop signal task. Brain Imaging Behav. 3, 262-276. doi: 10.1007/s11682-0099068-1

Loonstra, A. S., and Sellers, A. H. (1998). COWAT test norms across age, education, IQ, and gender: meta-analysis. Clin. Neuropsychol. 12, 272-273.

Mann, V. A., Sasanuma, S., Sakuma, N., and Masaki, S. (1990). Sex-differences in cognitive-abilities - a cross-cultural-perspective. Neuropsychologia 28, 1063-1077. doi: 10.1016/0028-3932(90)90141-A

McGlone, J. (1980). Sex-differences in human-brain asymmetry - a critical survey. Behav. Brain Sci. 3, 215-227. doi: 10.1017/S0140525X00 004398

Mordecai, K. L., Rubin, L. H., and Maki, P. M. (2008). Effects of menstrual cycle phase and oral contraceptive use on verbal memory. Horm. Behav. 54, 286-293. doi: 10.1016/j.yhbeh.2008.03.006

Mueller, S. C., Jackson, C. P., and Skelton, R. W. (2008). Sex differences in a virtual water maze: an eye tracking and pupillometry study. Behav. Brain Res. 193, 209-215. doi: 10.1016/j.bbr.2008.05.017

Munro, C. A., Winicki, J. M., Schretlen, D. J., Gower, E. W., Turano, K. A., Munoz, B., et al. (2012). Sex differences in cognition in healthy elderly individuals. Neuropsychol. Dev. Cogn. B Aging Neuropsychol. Cogn. 19, 759-768. doi: 10.1080/13825585.2012.690366 
Navon, D. (1977). Forest before trees - precedence of global features in visual-perception. Cogn. Psychol. 9, 353-383. doi: 10.1016/0010-0285(77) 90012-3

Navon, D. (1981). The forest revisited - more on global precedence. Psychol. Res. 43, 1-32. doi: 10.1007/BF00309635

Nielsen, S. E., Ahmed, I., and Cahill, L. (2013). Sex and menstrual cycle phase at encoding influence emotional memory for gist and detail. Neurobiol. Learn. Mem. 106, 56-65. doi: 10.1016/j.nlm.2013.07.015

Nielsen, S. E., Ertman, N., Lakhani, Y. S., and Cahill, L. (2011). Hormonal contraception usage is associated with altered memory for an emotional story. Neurobiol. Learn. Mem. 96, 378-384. doi: 10.1016/j.nlm.2011.06.013

Oberg, C., Larsson, M., and Backman, L. (2002). Differential sex effects in olfactory functioning: the role of verbal processing. J. Int. Neuropsychol. Soc. 8, 691-698. doi: 10.1017/S1355617702801424

Pena, D., Contreras, M. J., Shih, P. C., and Santacreu, J. (2008). Solution strategies as possible explanations of individual and sex differences in a dynamic spatial task. Acta Psychol. (Amst). 128, 1-14. doi: 10.1016/j.actpsy.2007.09.005

Pillemer, D. B., Wink, P., DiDonato, T. E., and Sanborn, R. (2003). Gender differences in autobiographical memory styles of older adults. Memory 11, 525-532. doi: 10.1080/09658210244000117

Pletzer, B., Kronbichler, M., Ladurner, G., Nuerk, H. C., and Kerschbaum, H. (2011). Menstrual cycle variations in the BOLD-response to a number bisection task: implications for research on sex differences. Brain Res. 1420, 37-47. doi: 10.1016/j.brainres.2011.08.058

Pletzer, B., Kronbichler, M., Nuerk, H. C., and Kerschbaum, H. (2013). Sex differences in the processing of global vs. local stimulus aspects in a twodigit number comparison task - an fmri study. PLOS ONE 8:e53824. doi: 10.1371/journal.pone.0053824

Pletzer, B., Kronbichler, M., Nuerk, H. C., and Kerschbaum, H. (2014a). Hormonal contraceptives masculinize brain activation patterns in the absence of behavioral changes in two numerical tasks. Brain Res. 1543, 128-142. doi: 10.1016/j.brainres.2013.11.007

Pletzer, B., Petasis, O., and Cahill, L. (2014b). Switching between forest and trees: opposite relationship of progesterone and testosterone to global-local processing. Horm. Behav. 66, 257-266. doi: 10.1016/j.yhbeh.2014.05.004

Postma, A., Jager, G., Kessels, P. C. R., Koppeschaar, P. F. H., and van Honk, J. (2004). Sex differences for selective forms of spatial memory. Brain Cogn. 54 24-34. doi: 10.1016/S0278-2626(03)00238-0

Razumnikova, O. M., and Vol'f, N. V. (2011). Information processing specialization during interference between global and local aspects of visual hierarchical stimuli in men and women. Human Physiology 37, 137-142. doi: $10.1134 / \mathrm{S} 0362119711020186$

Razumnikova, O. M., and Vol'f, N. V. (2012). [Sex differences in relationship between creativity and hemispheric information selection at the global and local levels]. Hum. Physio. 38, 33-42. doi: 10.1134/S0362119712 040111

Renteria, M. E. (2012). Cerebral asymmetry: a quantitative, multifactorial, and plastic brain phenotype. Twin Res. Hum. Genet. 15, 401-413. doi $10.1017 /$ thg. 2012.13

Rilea, S. L. (2008). A lateralization of function approach to sex differences in spatial ability: a reexamination. Brain Cogn. 67, 168-182. doi: 10.1016/j.bandc.2008.01.001

Roalf, D., Lowery, N., and Turetsky, B. I. (2006). Behavioral and physiological findings of gender differences in global-local visual processing. Brain Cogn. 60 , 32-42. doi: 10.1016/j.bandc.2005.09.008

Robertson, L. C., and Lamb, M. R. (1991). Neuropsychological contributions to theories of part/whole organization. Cogn. Psychol. 23, 299-330. doi: 10.1016/0010-0285(91)90012-D

Saether, L., Van Belle, W., Laeng, B., Brennen, T., and Overvoll, M. (2009). Anchoring gaze when categorizing faces' sex: evidence from eye-tracking data Vision Res. 49, 2870-2880. doi: 10.1016/j.visres.2009.09.001

Saucier, D. M., Green, S. M., Leason, J., MacFadden, A., Bell, S., and Elias, L. J. (2002). Are sex differences in navigation caused by sexually dimorphic strategies or by differences in the ability to use the strategies? Behav. Neurosci. 116, 403-410. doi: 10.1037/0735-7044.116.3.403

Schoning, S., Engelien, A., Kugel, H., Schafer, S., Schiffbauer, H., Zwitserlood, P., et al. (2007). Functional anatomy of visuo-spatial working memory during mental rotation is influenced by sex, menstrual cycle, and sex steroid hormones. Neuropsychologia 45, 3203-3214. doi: 10.1016/j.neuropsychologia.2007.06.011

Sharps, M. J., Welton, A. L., and Price, J. L. (1993). Gender and task in the determination of spatial cognitive performance. Psychol. Women Q. 17, 71-83. doi: 10.1111/j.1471-6402.1993.tb00677.x

Silverman, I., Choi, J., Mackewn, A., Fisher, M., Moro, J., and Olshansky, E. (2000). Evolved mechanisms underlying wayfinding: further studies on the huntergatherer theory of spatial sex differences. Evol. Hum. Behav. 21, 201-213. doi: 10.1016/S1090-5138(00)00036-2

Soleman, R. S., Schagen, E. E. S., Veltman, D. J., Kreukels, P. C. B., Cohen-Kettenis, P. T., Lambalk, C. B., et al. (2013). Sex differences in verbal fluency during adolescence: a functional magnetic resonance imaging study in gender dysphoric and control boys and girls. J. Sex. Med. 10, 1969-1977. doi: 10.1111/jsm.12083

Toga, A. W., and Thompson, P. M. (2003). Mapping brain asymmetry. Nat. Rev. Neurosci. 4, 37-48. doi: 10.1038/nrn1009

Voyer, D., and Bryden, M. P. (1990). Gender, level of spatial ability, and lateralization of mental rotation. Brain Cogn. 13, 18-29. doi: 10.1016/02782626(90)90037-O

Voyer, D., Voyer, S. D., and Tramonte, L. (2012). Free-viewing laterality tasks: a multilevel meta-analysis. Neuropsychology 26, 551-567. doi: 10.1037/ a0028631

Voyer, D., Voyer, S., and Bryden, M. P. (1995). Magnitude of sex-differences in spatial abilities - a metaanalysis and consideration of critical variables. Psychol. Bull. 117, 250-270. doi: 10.1037/0033-2909.117.2.250

Wada, J. A. (2009). Is functional hemispheric lateralization guided by structural cerebral asymmetry? The Canadian journal of neurological sciences. Can. J. Neurol. Sci. 36 Suppl. 2, S25-S31.

Weis, S., and Hausmann, M. (2010). Sex hormones: modulators of interhemispheric inhibition in the human brain. Neuroscientist 16, 132-138. doi: $10.1177 / 1073858409341481$

Weis, S., Hausmann, M., Stoffers, B., Vohn, R., Kellermann, T., and Sturm, W. (2008). Estradiol modulates functional brain organization during the menstrua cycle: an analysis of interhemispheric inhibition. J. Neurosci. 28, 13401-13410. doi: 10.1523/JNEUROSCI.4392-08.2008

Weiss, E. M., Ragland, J. D., Brensinger, C. M., Bilker, W. B., Deisenhammer, E. A., and Delazer, M. (2006). Sex diffierences in clustering and switching in verbal fluency tasks. J. Int. Neuropsychol. Soc. 12, 502-509. doi: $10.1017 /$ S1355617706060656

Weiss, E. M., Siedentopf, C., Hofer, A., Deisenhammer, E. A., Hoptman, M. J., Kremser, C., et al. (2003). Brain activation pattern during a verbal fluency test in healthy male and female volunteers: a functional magnetic resonance imaging study. Neurosci. Lett. 352, 191-194. doi: 10.1016/j.neulet.2003.08.071

Wharton, W., Hirshman, E., Merritt, P., Doyle, L., Paris, S., and Gleason, C. (2008). Oral contraceptives and androgenicity: influences on visuospatial task performance in younger individuals. Exp. Clin. Psychopharmacol. 16, 156-164. doi: 10.1037/1064-1297.16.2.156

Yonker, J. E., Eriksson, E., Nilsson, L. G., and Herlitz, A. (2003). Sex differences in episodic memory: minimal influence of estradiol. Brain Cogn. 52, 231-238. doi: 10.1016/S0278-2626(03)00074-5

Conflict of Interest Statement: The author declares that the research was conducted in the absence of any commercial or financial relationships that could be construed as a potential conflict of interest.

Received: 30 July 2014; accepted: 03 December 2014; published online: 22 December 2014.

Citation: Pletzer B (2014) Sex-specific strategy use and global-local processing: a perspective toward integrating sex differences in cognition. Front. Neurosci. 8:425. doi: 10.3389/fnins.2014.00425

This article was submitted to Neuroendocrine Science, a section of the journal Frontiers in Neuroscience.

Copyright (C) 2014 Pletzer. This is an open-access article distributed under the terms of the Creative Commons Attribution License (CC BY). The use, distribution or reproduction in other forums is permitted, provided the original author(s) or licensor are credited and that the original publication in this journal is cited, in accordance with accepted academic practice. No use, distribution or reproduction is permitted which does not comply with these terms. 